\title{
Modelling of Recycling in LCA
}

\author{
Tom N. Ligthart and Toon (A.)M.M. Ansems \\ TNO, Utrecht, \\ Netherlands
}

\section{Introduction}

\subsection{Life Cycle approach and life cycle stages}

In the Life Cycle approach Life Cycle Assessment (LCA) is a systematic way to evaluate the environmental impact of systems, products, materials or activities by following a "cradle-tograve" (a complete product chain) approach. This approach implies the identification and quantification of emissions and material and energy consumptions which affect the environment at all stages of the entire product life cycle.

The possible reasons for executing an LCA are for instance:

- To depict in as detailed as possible, the interaction of a product or activity with the environment

- To ensure a thorough insight into the interdependent nature of the environmental impacts of a human activity

- To supply decision-makers with information on the environmental impacts of activities and the possibilities for improvements

The entire product life cycle, shown systematically in Figure 1, consists of different stages:

- Extraction of raw materials

- Production of materials/semi-fabricates

- Manufacturing of product

- Service life or use phase

- $\quad$ End-of-Life

During all stages of the life cycle impacts exist on the surrounding environment. These impacts are caused by extracting raw materials and by emissions to air, water and soil. In LCA often several impact categories are used. The widely used Centrum voor Milieukunde Leiden/Institute of Environmental Sciences (CML) methodology (Guinee et al., 2002) for life cycle impact assessment uses the following categories:

- Abiotic depletion (ADP)

- Global warming (GWP)

- $\quad$ Ozone layer depletion (ODP)

- Human toxicity (HTP)

- Freshwater aquatic ecotoxicity (FAETP) 
- $\quad$ Marine aquatic ecotoxicity (MAETP)

- $\quad$ Terrestrial ecotoxicity (TETP)

- $\quad$ Photochemical oxidation (POCP)

- Acidification (AP)

- $\quad$ Eutrophication (EP)

- $\quad$ Land competition (LC)

With the help of Life Cycle Assessment (LCA) methodologies these contributions can be quantified and aggregated as will be explained in the following section.

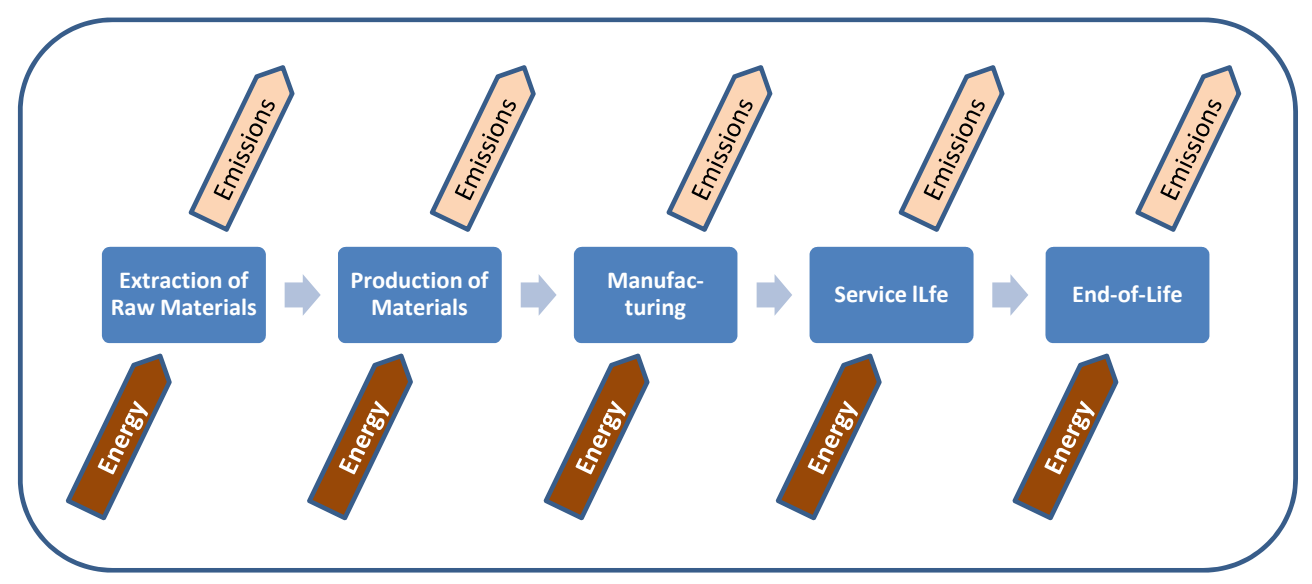

Fig. 1. The full Life Cycle of a product.

\subsection{Life Cycle Assessment}

The method of environmental Life Cycle Assessment (LCA) is seen as a suitable instrument for the evaluation of the environmental impacts of a product or an activity through its entire life cycle. LCA is a systematic way to evaluate the environmental impacts of product system or activities by following a "cradle-to-grave" approach. The product system consists of a set of activities (processes), all focused on the fulfilment of the required function. These activities can be executed at different places and in different time periods. Therefore it is not possible to produce results, which refer to "real" environmental effects, since this requires specific locations and specific periods.

The result of a life cycle assessment is expressed in terms of "potential" effects. These potential effects are indicators for the real effects on local, regional and global level.

The LCA methodology is structured along a framework (see Figure 2) with four main steps or phases (International Standard Organisation, 2006):

1. Goal and scope definition

2. Inventory analysis

3. Impact assessment

4. Interpretation 


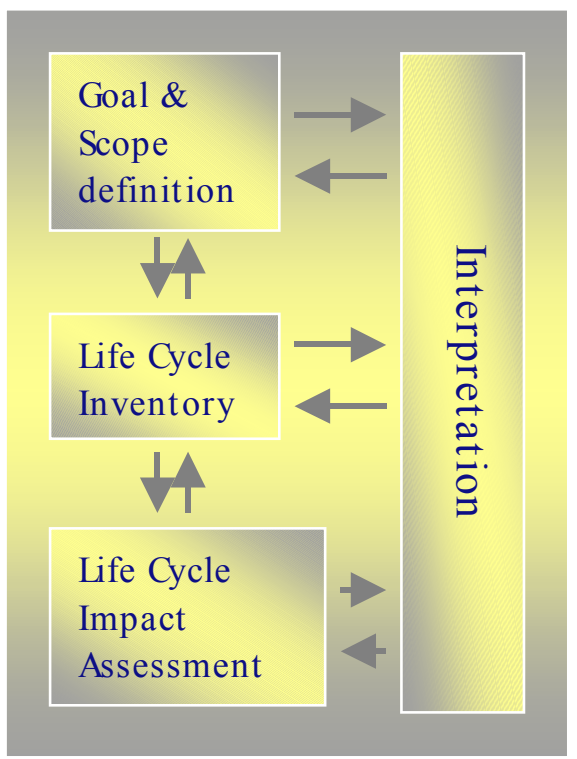

Fig. 2. The framework of LCA.

These phases are part of an iterative process; the main flow is according to the sequence mentioned before.

\section{Goal and scope definition}

This deals with the clear and unambiguous formulation of the research question and the intended application of the answer that the LCA study is supposed to provide. Important elements of the goal and scope definition are the choice of the functional unit, the selection of product (material) alternatives to be analysed, and the definition of the reference flows for each of the alternative systems.

\section{Inventory analysis}

This phase is concerned with the construction of the product systems. These systems are composed of unit processes, like industrial production, waste treatment, transport and so on.

The system boundaries and flow charts of linked unit processes are drawn for each alternative product system, and quantitative input and output data for each unit process are collected, e.g. raw materials and energy use figures, as well as emissions and waste amounts. Furthermore qualitative data for representativeness, data quality etc. are collected during this phase. For those unit processes that are multifunctional, i.e. that produce more than one product, an allocation step is made: all input and output data of the unit process are allocated to each of the products, according to chosen rule (e.g. on basis of mass ratio or economic value). A final step of the inventory analysis is the aggregation of the emissions of chemicals and the extractions of natural resources over the entire product system, in such a way that a quantitative match with the system's reference flow is achieved. The result of the 
inventory analysis is often a long list with disparate entries, such as carbon dioxide, nitrogen oxides, chloromethane and mercury.

\section{Impact assessment}

This phase aims to convert and aggregate the results of the inventory analysis into environmentally relevant items. In particular, we mention here the step of characterisation, in which the inventory results are transformed into a number of contributions to environmental impact categories, such as global warming, acidification, and ecotoxicity. Optionally the characterisation results may be normalised in order to relate the results to a reference value, such as the annual global or European extent of each impact. Finally, a weighting step may be performed, in which priority weights are assigned to the characterisation or normalisation results, and which may result into one final score for each alternative product system.

\section{Interpretation}

During the course of the LCA, many choices and assumptions are needed. Moreover, uncertainty may be introduced with every data item. The interpretation phase deals with the meaning and robustness of the information obtained and processed in the previous phases. The interpretation may include comparisons with previously published LCA studies on similar products, uncertainty and sensitivity analyses, data checks, external comments, and much more. It is also the place in which a final judgement and decision is outspoken.

\subsection{Recycling in LCA methodology}

\subsubsection{Recycling as part of the life cycle}

In 1.1 the different stages of the life cycle are illustrated and described. The End-of-Life stage can be filled in by following different ways and a hierarchy is followed here. The most optimal way for the End-of-Life is enlargement of the life time: Reuse. When this happens one speaks about a second life and probably the same function still exists. In this chapter we will not further discuss the effects of re-use.

The next most optimal way for the End-of-Life will be recycling with application in the same product (or group of products) without losses in quality of the observed material. It means that the physical and chemical properties of the materials or substances stay at the same quality level. In this case a closed loop recycling is considered. More on the types of recycling that are distinguished in LCA is discussed in section 1.4.

The lowest levels in the End-of-Life hierarchy are incineration, with or without energy recovery, and landfill. In this paper no attention is paid to these alternatives, however the different aspects of recycling are analysed more in depth and evaluated.

In society recycling is favourable and stimulated, because it saves primary resources and offers solutions for scarcity of raw materials. Moreover, resource efficiency mostly results in a strong reduction of the environmental impact of a product system. From that point of view recycling is stimulated by several stakeholders. In Figure 3 the specific role of recycling in the life cycle is highlighted. 


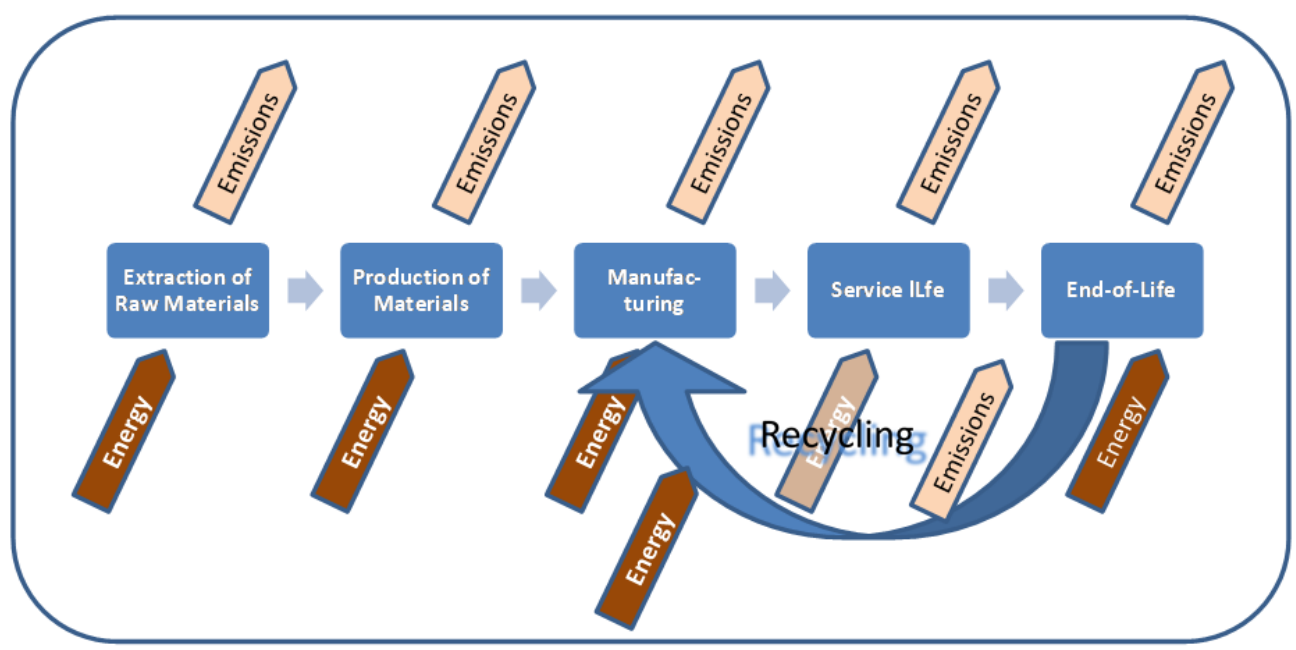

Fig. 3. The situation and place of recycling in the life cycle.

\subsubsection{The difficulties of introducing recycling into LCA}

Laymen to LCA often assume in a straight forward way that products are totally manufactured out of primary resources and that recycled resources, secondary resources, are applied in other products. In their view closed loop recycling does not occur. However, in practice often mixtures of primary and secondary resources are used in new products and also at the End-of-Life stage several ways of treatments exist. Combinations of closed loop recycling, open loop recycling and incineration will be applied for certain end-of-life flows.

The difficulties are now to set the right boundaries for the different flows, ending in different product systems. Which observed material flow belongs to the first observed product system and which one to the second or other observed systems? Another question is which rules or scientifically based calculation rules exist to apply broadly accepted divisions over the different product systems.

The theoretical aspects and answers of these aforementioned questions are described in the following sections.

\section{Modelling of recycling in LCA}

Recycling processes can be divided based on where and how the recycled material is used again:

- Closed loop recycling

- Open loop recycling

- Semi-closed loop recycling

The three schemes are shown in Figure 4 and now explained in further detail. 


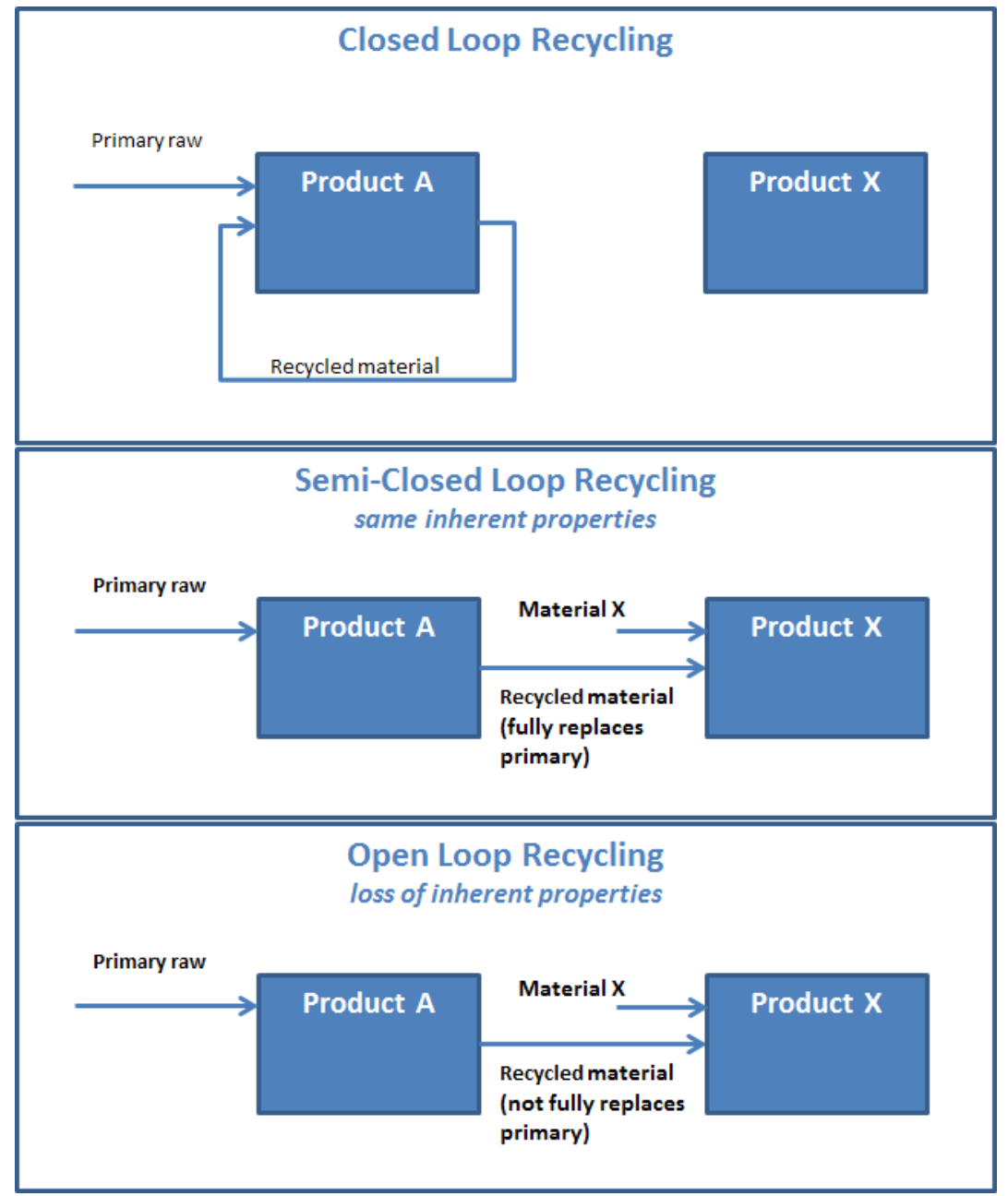

Fig. 4. The three recycling schemes.

\section{Closed loop recycling}

This occurs when the materials associated with a product are recycled and used again in the same product system. The material properties are not changed in comparison to the original primary material. Bottle-to-bottle recycling is an example of closed loop recycling.

Open loop recycling

Occurs when the recycled material goes to another product system and the inherent material properties are changed to such an extent that the recycled cannot be used in its original system. Plastic recycling is open loop recycling when the recycled plastic from i.e. packaging is recycled into other products like e.g. plastic poles. This type of recycling is also called down cycling as there is loss of quality. 


\section{Semi-closed loop recycling}

When the recycled material in used in another product system, without the material's inherent properties undergoing any change. This is the case when construction steel is recycled into e.g. steel plates for ship building.

Most LCA practitioners e.g. Guinee, 2002 and the ISO 14044 standard (ISO, 2006) take semiclosed loop recycling the same as closed loop recycling (see Figure 5).

Most often a product system does not fully recycle all material that comes available after use. Even if this was the case the recycling process will normally lead to some loss of material and primary material is needed to keep the circle closed. The efficiency of the endof-life system can be described by the following indicators (Norgate, 2004):
- $\quad$ Collection rate $(\%)$
$=100 * \frac{\text { Amount of scrap collected }}{\text { Amount of scrap produced }}$
- $\quad$ Recovery rate $(\%)$
$=100 * \frac{\text { Amount of scrap recovered }}{\text { Amount of scrap available }}$
- $\quad$ Recycling efficiency (\%)
$=100 * \frac{\text { Amount of scrap reprocessed }}{\text { Amount of scrap recovered }}$
- $\quad$ Recycling rate (\%)
$=100 * \frac{\text { Amount of scrap reprocessed }}{\text { Amount of scrap available }}$

$=100 *$ Recovery rate $*$ Recycling efficiency

- Recycled content $(\%) \quad=100 * \frac{\text { Amount of scrap reprocessed }}{\text { Total Amount of material }}$

The place of these indicators in the life cycle of a system are shown in Figure 6.

\section{Technlcal descriptlon of a product system}

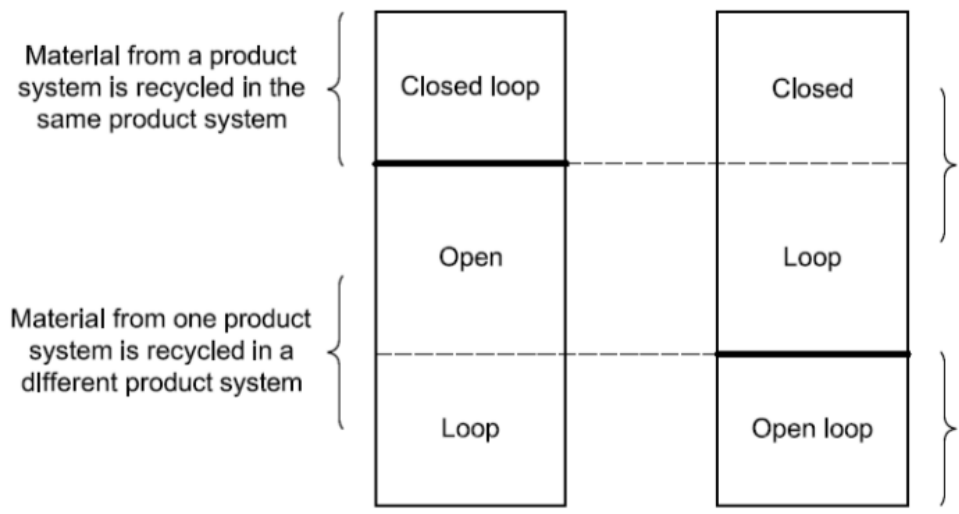

Allocatlon procedures for recycllng

Material is recycled without changes to inherent properties

Recycled material undergoes changes to inherent properties

Fig. 5. The technical description of recycling in a product system and the allocation procedures for recycling (ISO, 2006). 


\subsection{Allocation for recycling processes}

When at the end-of-life of a product system post-consumer waste occurs allocation may become necessary. This as the product system under study can provide waste materials that are used by other systems as a raw material. The question is then how to divide the impacts of e.g. recycling over the system that delivers the waste material and over the system that uses this material as input for a secondary material. This problem especially occurs in open loop recycling.

ISO 14044 (ISO, 2006) describes that the inputs and outputs shall be allocated to the different products according to clearly stated procedures that shall be documented and explained together with the allocation procedure. Whenever several alternative allocation procedures seem applicable, a sensitivity analysis shall be conducted to illustrate the consequences of the departure from the selected approach.

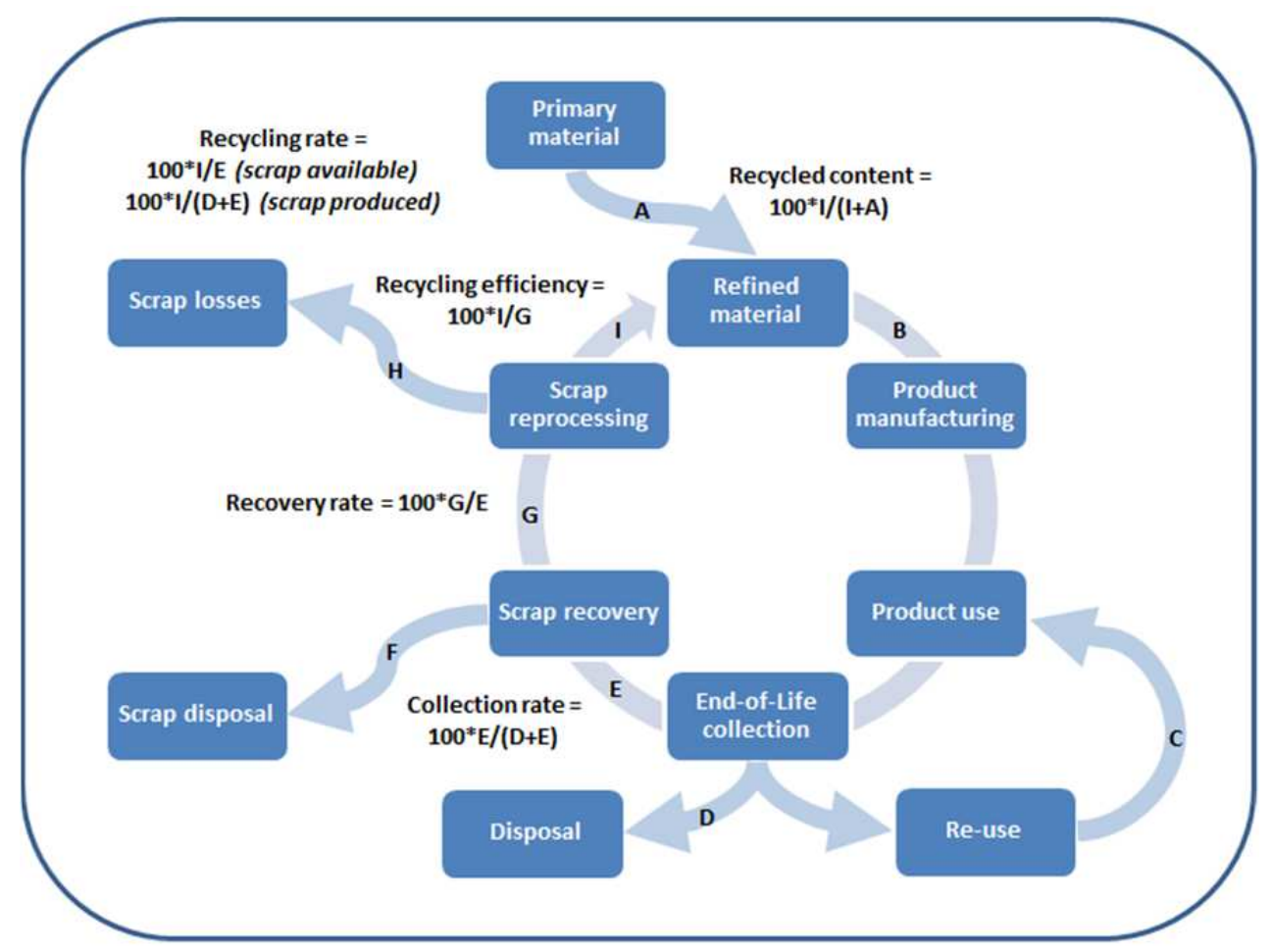

Fig. 6. Product system and recycling indicators (after Norgate, 2004).

So, what allocation procedures are applied in practice? The most common are:

1. Cut-off

2. System expansion

3. Economic allocation

4. Input oriented 
5. Output oriented/Substitution

6. Value-corrected substitution

7. Multiple recycling method

These allocation procedures will now be explained and discussed.

Cut-off

One of the easiest to apply is the cut-off method (see Norgate, 2004 and Ekvall \& Tillman, 1997). In this method the environmental impacts directly caused by the production of a product are assigned to that product, i.e. primary and secondary production are allocated to the product under study. Also an eventual waste treatment, other than recycling, is allocated to the product. No data from outside the life cycle of the investigated product are needed for this approach (see Figure 7). The extensive ecoinvent database with life cycle inventory data also uses this approach for recycling and recovery (Hischier et al., 2010).

In the cut-off approach the recycled content is of importance as this may be a way to reduce the environmental impact of the system as often the recycled material has a lesser impact than the primary material. An increase in collection rate is also beneficial as this reduces the impact of the waste disposal. The cut-off is seen to advocate the use of a high recycled content (Frischknecht, 2010).

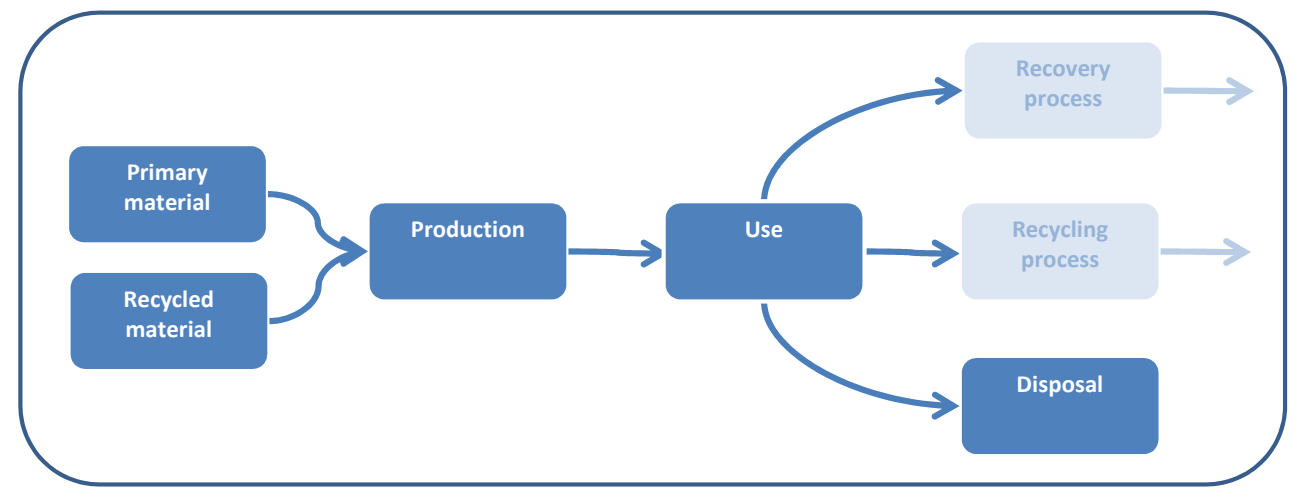

Fig. 7. The product system for the cut-off approach.

\section{System expansion}

ISO 14044 prefers to avoid allocation by expanding the system so that in fact a closed system comes into being. The aluminium industry for instance states (European Aluminium Association [EAA], 2010) that as aluminium recycling leads to no loss in inherent properties the recycling can be seen as closed loop recycling and only the replenishment of primary aluminium needed to balance the eventual losses of aluminium from the system has to be added to give a closed system (see Figure 8).

For more complex product systems application of system expansion can increase the complexity of the system by adding more functions to the system and it may even lead to new allocation issues (see e.g. Zamagni, 2008). Allocation, instead of system expansion, thus often applied in LCA studies. 


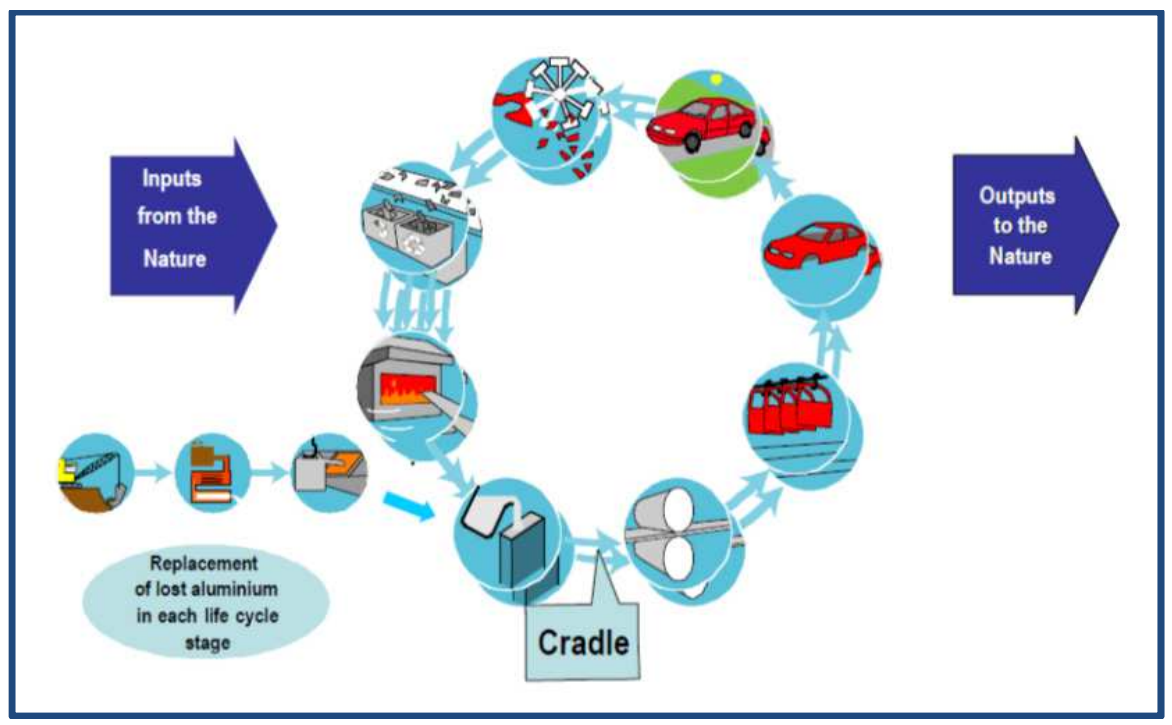

Fig. 8. Closed system of aluminium in products (EAA, 2010).

\section{Economic allocation}

In the Dutch Handbook on LCA (Guinee, 2002) economic allocation is advised as a baseline method for most allocation situations, including recycling, in a detailed LCA. Economic allocation is based on the economic value of the inputs and outputs of a recycling system. Guinee et al., 2004 give an example of the recycling of aluminium from a used engine.

Let us first have a look at an open loop recycling system. The used engine, used material in Figure 9, yields $€ 100$ for the collection and dismantling process. Another yield of this process is the scrap that is sold onto the market. The reprocessed material is used in other products than engines. The scrap yields $€ 150$, which brings the total yield of the process to $€ 250$.

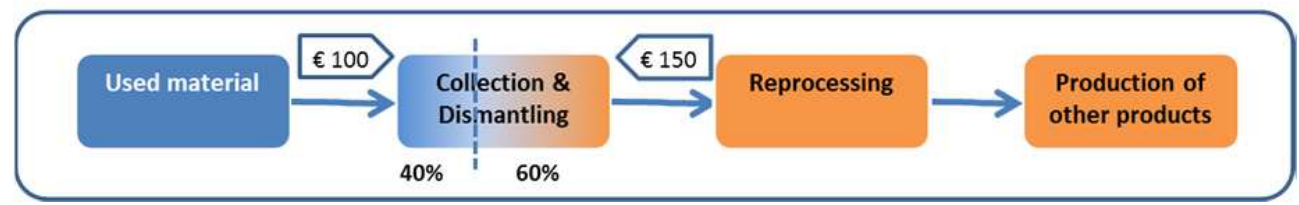

Fig. 9. Example of economic allocation of inputs and outputs of an open loop recycling system (based on Guinee et al., 2004). The 'used material' system is based on its economic value allocated $40 \%$ of the impact of the collection and dismantling.

As the used material contributes to $40 \%$ (100/250) of the collection and dismantling process, $40 \%$ of the environmental burden of the process is allocated to the system that delivers the used material. The remaining $60 \%$ is allocated to the system that subsequently uses the secondary material. This economic allocation seeks in other words where in the end-of-life the economic flows are in equilibrium or where the point of zero value lies. 
In case of a (semi-)closed loop recycling scheme, shown in Figure 10, reprocessed material (partly) flows back into the original product system. Let us assume that 1 of the $5 \mathrm{~kg}$ material used flows back. Based on the economic allocation $40 \%$ of the collection and dismantling process is allocated to the original product system. However, also $20 \%(1 \mathrm{~kg}$ from $5 \mathrm{~kg}$ ) of the remaining $60 \%$, resulting in $12 \%$, that is allocated to the reprocessed material must be added as this flows back to the original system. In total $40 \%+12 \%=52 \%$ of the collection and dismantling process is now allocated to the original product system.

This approach of economic allocation can be seen as a modification of the cut-off method of allocation. It has in common with it that no avoided primary material production due to recycling is allocated to the product system under study.

A special situation occurs when the waste material has a positive economic value. In this case the point of zero value cannot be found. The waste material can then be seen as a coproduct of the system. The relative value of the waste material can then be the basis for subtraction of part of the environmental impact from the product system. This specific case will not be discussed further in this chapter as it in practice not often occurs.

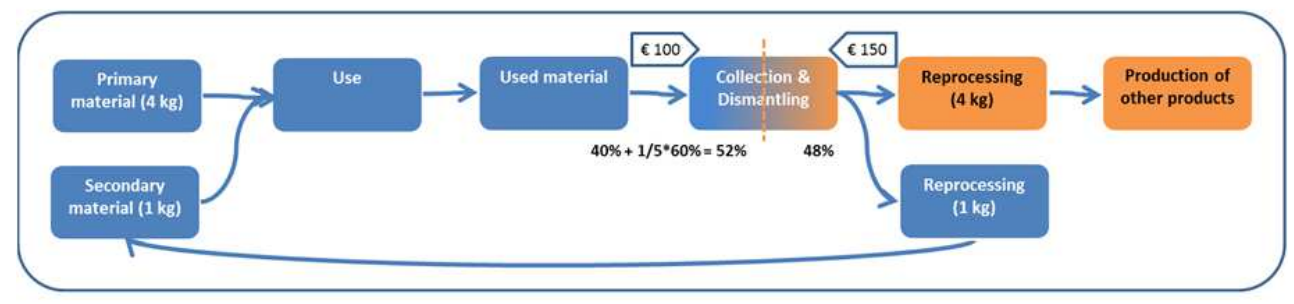

Fig. 10. Example of economic allocation of inputs and outputs of a semi-closed loop recycling system (based on Guinee et al., 2004). The used material is based on its economic value allocated $40 \%$ of the impact of the collection and dismantling.

Using economic allocation reflects that product systems are part of the economic system. As product systems are generally designed to generate economic value using economic data for allocation seems appropriate. However, the market of waste treatment may be a market distorted by regulations and fees asked for waste treatment may not always reflect real market prices. This can lead to not estimating the point of zero value fully correct.

\section{Input oriented}

The input oriented approach only takes the inputs of primary and secondary, including collection and further recycling steps, into account plus the waste disposal. The output of material going to recycling is not considered to be part of the product system. It is the same approach as the cut-off allocation (see Figure 7).

\section{Output oriented, Substitution or Avoided burden/impact}

This allocation method is based upon the substitution of primary raw material by the reprocessed (secondary) material at the end-of-life stage. It is also called the substitution method or avoided burden or avoided impact method (see Figure 11). It can especially be 
applied to semi-closed loop recycling in cases where the reprocessed material has the same or closely resembles the inherent properties of the primary material (see e.g. ISO, 2006, Nicholson et al., 2009). According to ISO 14044 (ISO, 2006) there is in the case of closed-loop recycling no need for allocation since reprocessed secondary material fully replaces primary material.

Effectively the product system includes or replenishes the amount of primary material that is 'leaking' from the system as it goes to the waste disposal. In this way the loop is kept closed.

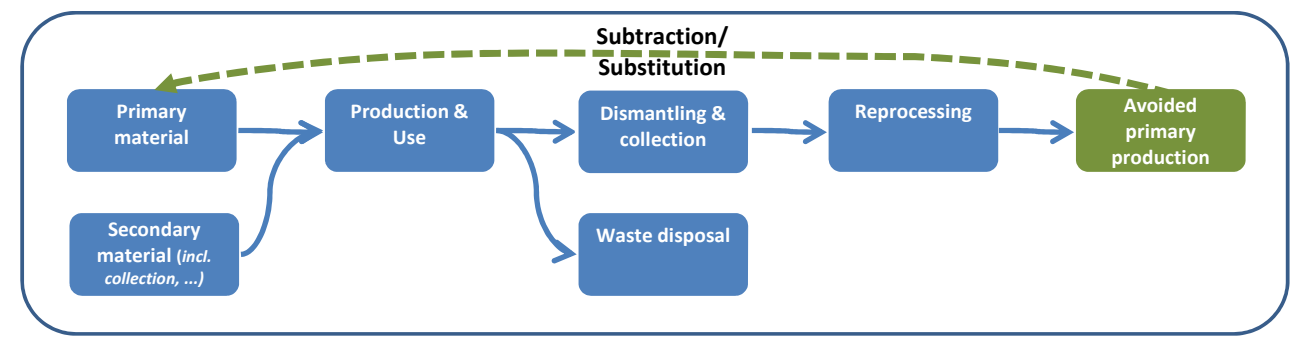

Fig. 11. The output oriented or substitution allocation approach.

The substitution approach is widely used in LCAs where recycling at the end-of-life is involved (Frischknecht, 2010). Whether in all cases it is really so that the inherent properties do not differ significantly is however the question. The substitution approach puts the focus onto the benefits of recycling. Increased recovery rates leads to more subtraction of primary material production and so lowers the environmental impacts.

\section{Value-corrected substitution}

The value-corrected substitution allocation addresses the point that the reprocessed material may not have the same inherent properties as the primary material (Guinee, 2002; EAA, 2010). This may be the case for i.e. aluminium alloys or paper. The method assumes that the proportionality of the environmental burdens caused by primary material production and the (economic) value of the recycled material (Vroonhof et al., 2002). Werner and Richter, 2000 consider the market price as an expression of the material quality within a technoeconomic system. They see the relative market prices of the raw materials -not the scraptherefore as a useful parameter to describe the "qualitative" gradation or inherent property of a material.

The method is suited for open-loop or semi-closed loop recycling. The method uses the ratio of secondary material price to the primary material price $\left(P_{\text {prim }} / P_{\text {sec }}\right)$ as the indicator of the inherent property of the secondary material. The secondary material may substitute $P_{\text {prim }} / P_{\text {sec }}$ of primary material.

We will clarify this method with an example (see Table 1 and Figure 12). The environmental burden of the materials is thus the sum of net difference in the value-corrected inflow and outflow of (primary) material plus the amount of material to be reprocessed in the product system. The method does include the recovery or recycling processes at the end-of-life stage of an LCA. 
It must be noted that the value-corrected amounts in Table 1 do not give a closed mass balance, that is only the case for the uncorrected amounts.

\begin{tabular}{|lrrr|}
\hline Flows & Amount (kg) & Value (\%/kg) & Value-correction \\
\hline In: Primary & 70 & 100 & 70 \\
In: Secondary & 30 & 90 & 27 \\
In: Total & $\mathbf{1 0 0}$ & - & $\mathbf{9 7}$ \\
Out: Scrap to recovery & -80 & 90 & -72 \\
Out: Scrap to disposal & -20 & 0 & 0 \\
Out: Total & $\mathbf{- 1 0 0}$ & - & $\mathbf{- 7 2}$ \\
Balance & $\mathbf{0}$ & - & $\mathbf{2 5}$ \\
\hline
\end{tabular}

Table 1. Example of value-corrected substitution.

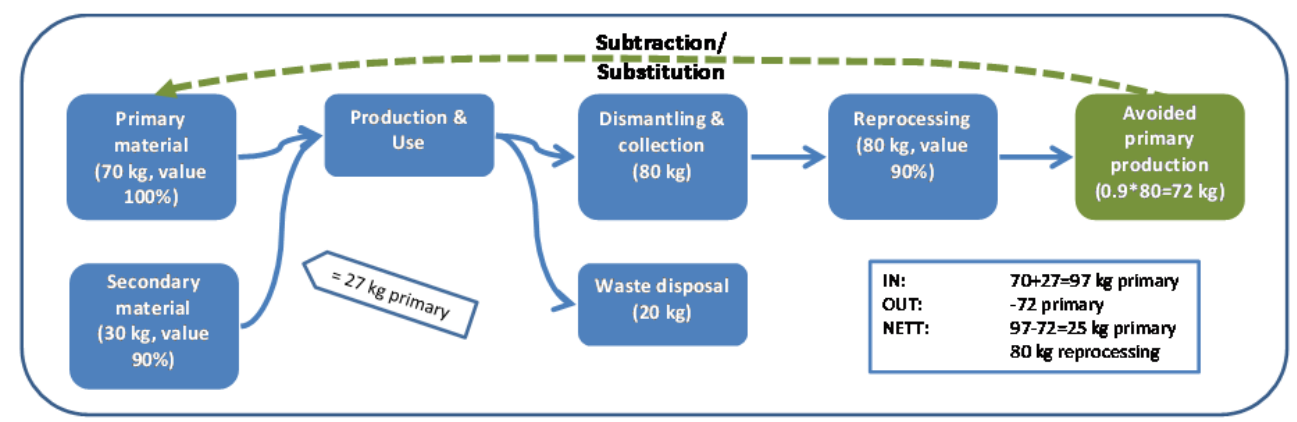

Fig. 12. Example of product system when applying the value-corrected substitution.

A precondition for this allocation procedure is a stable price relation of primary and secondary material (Werner \& Richter, 2000). However, in some cases the primary to secondary material price may vary considerably during time and this will reflect in changed allocation parameters during time. The environmental impact of a system may thus vary with time while the physical characteristics of the system remain the same.

\section{Multiple recycling method}

In the steel industry scrap is used in both the primary steel route (Basic Oxygen Furnace) and in the secondary steel route (Electric Arc Furnace). Basically the primary route provides the material for the secondary route (see e.g. Thomas \& Broadbent, 2007). The International Iron and Steel Institute wanted to address this interconnection for their life cycle inventory data and developed the multiple recycling method (Amato et al., 1996; Thomas \& Broadbent, 2007).

The multiple recycling method uses a number of parameters (Thomas \& Broadbent, 2007) to calculate the results of applying the method:

$R R=$ Recovery Rate

$Y=$ Yield of recovery process

$X_{p r}=$ Impact of primary production

$X_{r e}=$ Impact of secondary production

$n=$ number of life cycles 
$Q_{\text {ini }}=$ Initial amount of primary product

$Q_{\text {cum }}=Q_{\text {ini }} \times\left(\left(1-R R^{n+1}\right) \div(1-R R)\right)=$ Cumulative amount of product for $n$ cycles

The yield ' $Y$ ' of the recovery process is called recycling efficiency in Figure 5.

As the term $\left(1-R R^{n+1}\right)$ goes to 1 for large values of $\mathrm{n} Q_{\text {cum }}$ becomes $Q_{\text {ini }} \div(1-R R)$. This means that with a Recovery Rate of e.g. 0.8 the cumulative amount of steel originating from 1 tonne primary steel is 5 tonnes. The impact of a product system can be described by $X=\left(X_{\text {pri }}-X_{r e}\right) \times\left((1-R R \times Y) \div\left(1-(R R \times Y)^{n}\right)\right)+X_{r e}$

With increasing number of consecutive life cycles (see Figure 13) the environmental impact reduces as the recovered material has a lower impact than the primary material, see Figure 14. After a number of life cycles the impact reaches an almost constant value.

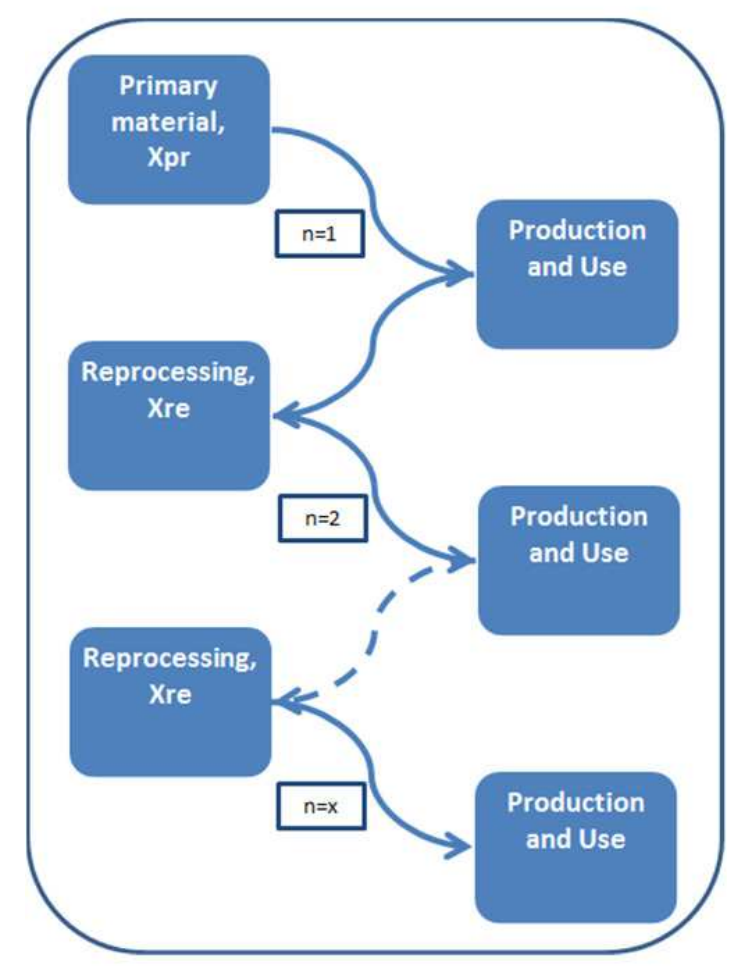

Fig. 13. Multiple recycling system with $\mathrm{n}$ life cycles after Thomas \& Broadbent, 2007. $X_{\mathrm{pr}}$ Impact of primary production; $X_{\text {re }}$ impact of recovery process.

The multiple recycling method can also be applied to other metals and materials where open loop or semi-closed loop recycling appears and the inherent properties of the material do not change or only slightly change. Recovery rates for different types of steel application can be found in the study by Five Winds International (2007). 
In the next section we will discuss which methodological choices have to be made when applying these allocation methods.

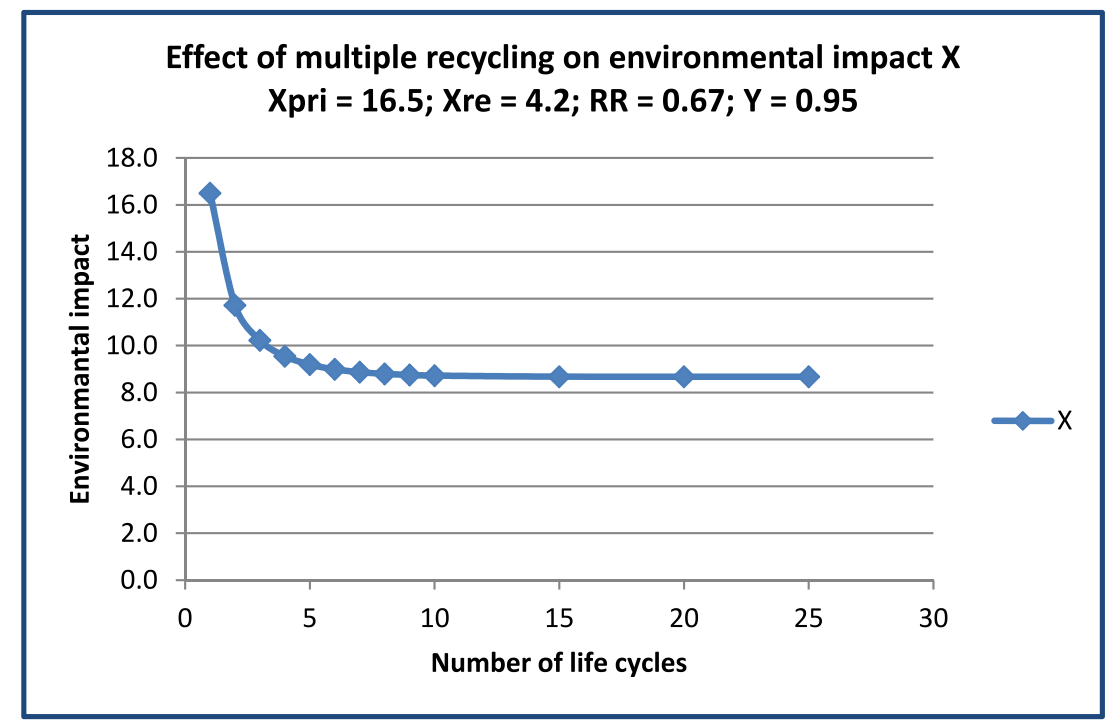

Fig. 14. The effect of multiple recycling cycles on the environmental impact assuming certain values for the parameters.

\subsection{What choices are to be made?}

In the case of closed loop recycling, which not often occurs in practice, methodological choices on allocation are absent. As most recycling or recovery cases are open loop or semiclosed loop these methodological choices are often to be made. Only when using the system expansion, cut-off or input oriented approaches these choices are not necessary due to the nature of these methods.

In the case of applying economic allocation the methodology is simple and the main choices occur when the revenues are not fully available or when the markets are distorted. This can be the case when fees on e.g. the recovery process is determined by regulations or by taxlike costs. Guinee et al., 2004 give strategies to overcome these issues like prices based on the actual costs made or the actual material price received by the seller.

In the output oriented or substitution method the main choice is which primary (raw) material is being avoided by the secondary material. For steel recycling the scrap substitutes pig iron. Pig iron is produced by the blast furnace and used in steelmaking in the basic oxygen furnace (see e.g. Classen et al., 2009). However, some LCA practitioners use primary steel as the avoided product although primary steel is the product of, and not a raw material for, steelmaking. This will give a higher environmental impact to be subtracted. This overestimation also happens in e.g. paper or cardboard recycling when one substitutes the primary product instead of primary pulp. Merrild et al., 2008 show the importance of making the correct choices of the recovery process for waste paper and 
especially the avoided type of primary pulp/paper as different choices may lead to significantly differing LCA results. In general to make the correct choice for the avoided material one has to have a close look which raw materials enter the primary production system.

Choosing the correct avoided primary material is also essential when applying the value corrected substitution method. Especially in cases of open loop recycling as then the avoided primary material may not always be clear or may in fact be more than one material. This is for instance the case with some plastic recycling schemes where the secondary material replaces concrete and/or wood. Another issue is whether one takes the price of scrap or of the secondary material itself.

The main choice to be made in the multiple recycling method is the number of times a material can be recycled. For metals an infinite number is often assumed. However, a buildup of alloying elements can reduce the number of life cycles that a material can be reprocessed (Amato et al., 1996). Applying the method to other materials like paper assuming an infinite number of loops may be incorrect and may underestimate the environmental impact of the product system.

It has been mentioned before that the cut-off approach promotes a high recycled content and the substitution approach a high recovery rate. According to Frischknecht, 2010 the cut-off approach is more appropriate when wanting to stress the preservation of natural stocks like those of metal ores. In environmental labelling the recycled content is often one of the indicators. According to Dubreuil et al., 2010 the cut-off or recycled content approach is most useful as a metric for materials that would otherwise be incinerated or landfilled as waste. The substitution approach should be more risk seeking as it depends on the actual or future recovery rate of post consumer materials.

\section{Application of allocation methods in LCA}

\subsection{Introduction}

For four of the allocation approaches that can be applied to several different type of materials the effect of applying those approaches will be shown in this section. Three different types of material (paper, metal, plastic) have been chosen. For paper the example is based on the recycling of post-consumer graphical paper. While steel has been used in the metal case. Finally, the example of post-consumer plastic recycling has been based on bottle grade PET.

\subsection{Effects of applying different allocation approaches}

For paper the example is based on the assumptions shown in Table 2. The results are shown for two often used single indicators; the global warming potential (GWP) and the cumulative energy demand (CED) including renewable energy sources.

For the economic allocation it has been assumed that $90 \%$ of the impact of the collection is allocated to the system under study as the value of waste paper is relatively low compared to the costs of collection. The assumption has been made that secondary pulp has a value of 
$90 \%$ of that of primary pulp. This value is needed for the value-corrected substitution approach.

\begin{tabular}{|l|r|}
\hline Material and Process Flow & Amount (kg) \\
\hline IN: Primary pulp & 0.6 \\
\hline IN: Secondary pulp & 0.4 \\
\hline Sheet production & 1 \\
\hline OUT: Incineration & 0.15 \\
\hline OUT: Landfill & 0.05 \\
\hline OUT: Sorting \& recycling & 0.8 \\
\hline
\end{tabular}

Table 2. Material and process flows assumed for the example for graphical paper.

Applying different allocation approaches clearly has an impact on the results of the environmental impact of the system of graphical paper (see Figure 14). Remarkable is that the highest global warming potential is found for the substitution approach which takes into account the avoided primary production. The reason for this is that the secondary pulp process is based on non-renewable energy sources while the primary pulp has a considerate input of renewable fuels of which the incineration is carbon neutral.

The two allocation approaches that include the avoided primary production (5. And 6. In Figure 15) do show a reduced cumulative energy demand. This is mainly due to the avoided production of primary pulp. The avoided primary energy production due to energy recovery from the waste send to incineration is of lesser importance in this example.

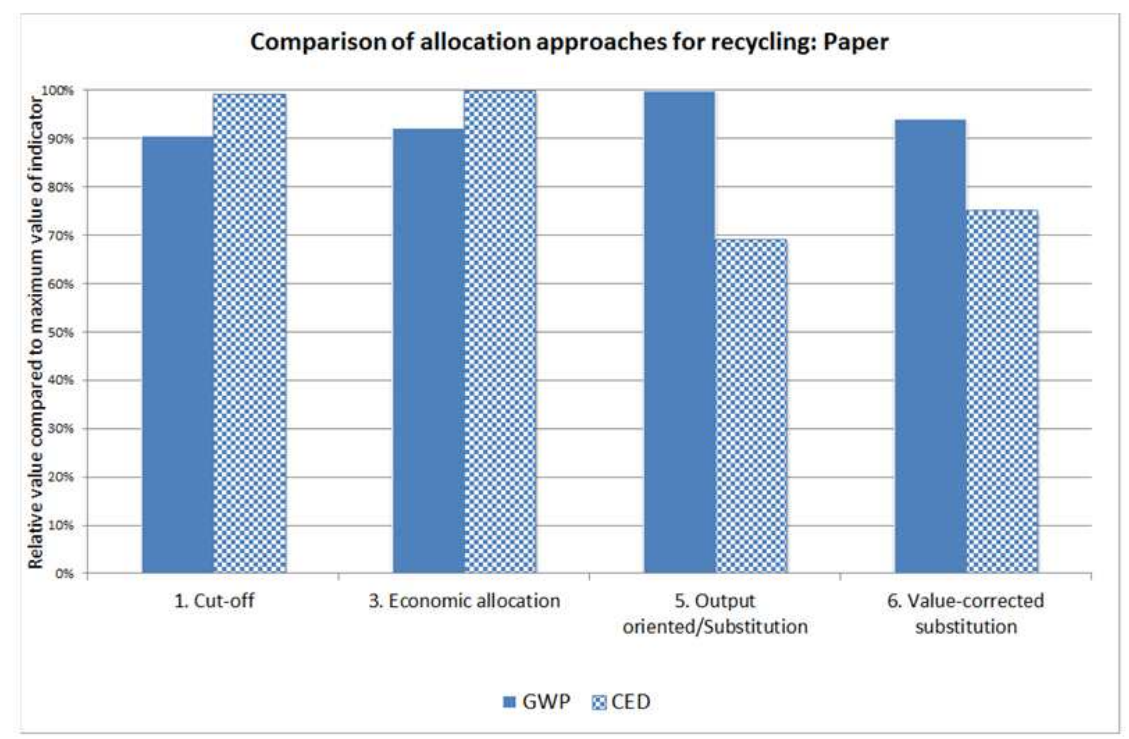

Fig. 15. Relative indicator values for both GWP and CED for the product system of graphical paper. 
Specific circumstances in a product system may thus affect the outcome of a allocation approach. As seen in this example for GWP and CED the results may also differ per environmental impact. As the impact of collection is relatively small the approach of economic allocation, where a part of the collection for recycling is allocated to the system that delivers the waste, the results only very slightly differ from the basic cut-off approach.

In the case for steel the recycled content has been assumed to be $40 \%$ while $90 \%$ of the postconsumer material is going to recycling (see Table 3). As steel scrap has considerable value compared to the costs of collection only $10 \%$ of the collection impacts are allocated to the system that provides the post-consumer material. The value of secondary steel is assumed to be $90 \%$ of that of primary steel.

\begin{tabular}{|l|r|}
\hline Material and Process Flow & Amount (kg) \\
\hline IN: Primary steel & 0.6 \\
\hline IN: Secondary steel & 0.4 \\
\hline Sheet production & 1 \\
\hline OUT: Landfill & 0.1 \\
\hline OUT: Sorting \& Recycling & 0.9 \\
\hline
\end{tabular}

Table 3. Material and process flows assumed for the example for steel.

Due to the limited impact of the collection of the waste the cut-off and economic allocation do not differ significantly (see Figure 16).

The allocation approaches that do include the avoided primary production show (see Figure 16) a considerable lower impact than the cut-off approach and economic allocation. Although the value corrected substitution works differently, it expresses the secondary material as a corrected amount of primary material, the results for GWP and CED do not differ greatly from those found for the 'normal' substitution approach.

The last example shown is that of PET used in bottles. The amount of secondary PET is high compared to the actual situation, but is used to enhance differences between the allocation approaches (see Table 4). For the economic allocation approach it is estimated that $15 \%$ of the impacts of collection are allocated to the system that delivers the waste. It has been assumed that the value of secondary PET is $32 \%$ of that of primary PET, this value is used by Shen et al., 2010.

\begin{tabular}{|l|r|}
\hline Material and Process Flow & Amount (kg) \\
\hline IN: Primary PET & 0.6 \\
\hline IN: Secondary PET & 0.4 \\
\hline Bottle production & 1 \\
\hline OUT: MSWI & 0.1 \\
\hline OUT: Sorting \& recycling & 0.9 \\
\hline
\end{tabular}

Table 4. Material and process flows assumed for the example for PET bottles.

As seen for the other examples the results for the cut-off and economic allocation do actually not differ from each other (see Figure 17). Only in cases where the impacts of the collection itself have a considerable contribution a difference between those two approaches can be expected. 


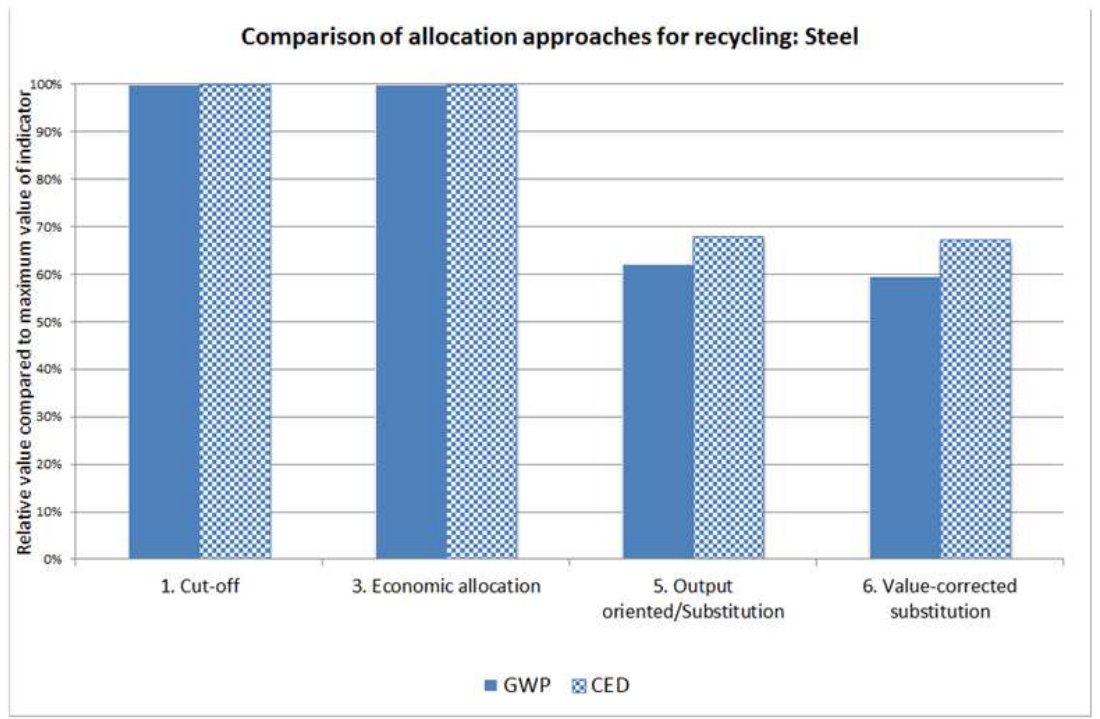

Fig. 16. Relative indicator values for both GWP and CED for the product system of steel sheet.

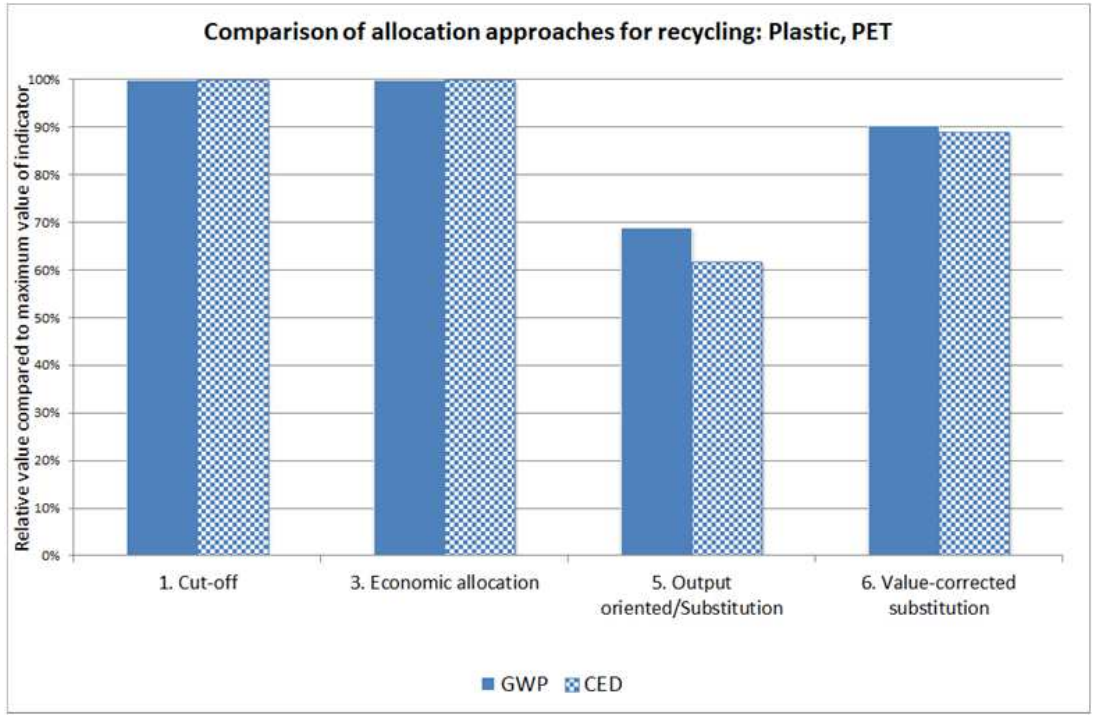

Fig. 17. Relative indicator values for both GWP and CED for the product system of PET bottles.

The two substitution approaches do indeed show a reduction of the GWP and CED results (see Figure 17). As the value of secondary PET is relatively low compared to secondary PET the value-corrected substitution approach gives a lesser amount of primary to be subtracted $(32 \%$ of $0.9 \mathrm{~kg}=0.29 \mathrm{~kg})$ than the 'normal' substitution method $(0.6 \mathrm{~kg}$ primary * recycling rate of $90 \%=0.54 \mathrm{~kg}$ ). The GWP and CED results are thus higher for the value-corrected substitution approach (see Figure 17). 
The three examples show that in general those allocation approaches that do not include the avoided impacts of primary materials production show higher environmental impacts than those approaches that do include this avoided primary production. However, if the recycling process has a higher impact than the primary production the substitution approach may show higher values than the cut-off approach. This was the case for paper recycling and the GWP impact of the product system.

In case the value of the secondary material is low compared to that of the primary material, see the example of PET, the value-corrected approach will generally show higher impacts than the substitution or avoided impact approach.

\section{Examples of recycling in LCA}

\subsection{Approach}

A number of LCA studies focussing on recycling has been studied. An important source was the report issued by British Waste \& Resources Action Programme (WRAP) from 2006 (WRAP, 2006) and updated in 2010 (WRAP, 2010). These reports have compared a number of LCA studies on material recycling and comparisons with other waste treatment options. The same type of materials as used in the previous section are the focus of this section.

\subsection{Recycling of paper and cardboard}

The recycling of paper and cardboard was in some cases environmentally preferred to incineration, but in other cases the opposite was true (WRAP, 2006, 2010). In the case of giving environmental benefits from energy recovery from waste incineration it is highly

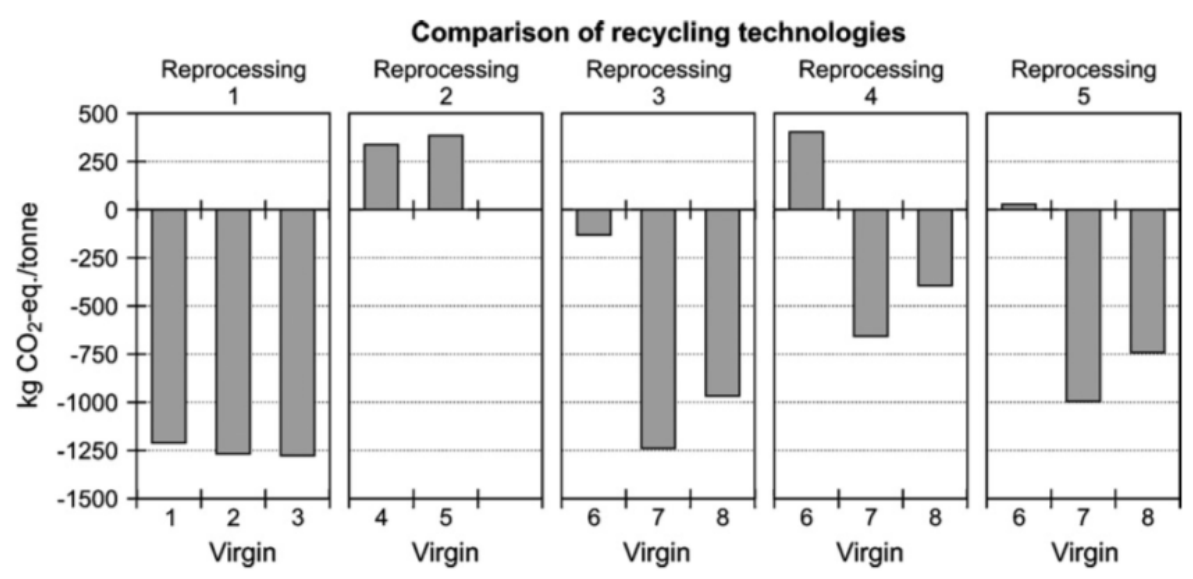

Fig. 18. Global warming potentials for recycling 1 tonne of waste paper for 14 possible recycling combinations (the top label gives a specific reprocessing technology, the bottom label gives the virgin technology that is avoided (Merrild et al., 2008). Reprocessing technologies: 1. Newspaper; 2. Fine paper; 3. Coreboard; 4. Solid cardboard; 5. Liner and fluting. Avoided technologies: 1. Newspaper; 2.,3. Printing paper; 4.,5. Fine paper; 6.-8. Cardboard. 
important to choose the actual energy mix that is substituted by the energy recovered form the waste incinerator. As paper and cardboard are from renewable sources replacing energy from fossil fuels has a clear impact on the global warming impact of the system studied.

Another important point is the choice of the virgin material that is replaced by the recycled material. The recovered fibre process may deliver different kinds of products like testliner, wellenstoff and fluting. According to Arena et al., 2004 the energy requirements, which greatly influence the environmental performance, differ only slightly and the results of an LCA are thus less sensitive to the choice of the secondary material. Arena et al., 2004 compared paper and board recycling in Italy with landfill and waste incineration. They have applied system expansion in the case of packaging paper. This means that in e.g. the incineration alternative the system not only processes waste paper and board but also produces primary packaging paper. This last process takes place in Sweden the main source for imported packaging paper in Italy. In the case of Italy the energy balance of waste paper and board incineration is much better than that of recycling (Arena et al., 2004). When the avoided paper and cardboard production is allocated by substitution or value-corrected substitution the choice of the avoided product may greatly affect the LCA's results (Finnveden et al., 2000). Merild et al., 2008 conclude that the energy mix of the virgin paper production for the various paper and cardboard types is a decisive factor for the LCA's result. For the fourteen possible combinations of recycling and virgin technologies for paper and board production, which included the efficiency and quality loss of and due to the recycling processes, some combinations show a beneficial impact of recycling while others do not (see Figure 18).

Pulp is the raw material for the production of paper and cardboard. It is therefore also possible to see virgin pulp as the avoided product when using substitution allocation. It appears that most studies used in the WRAP report (WRAP, 2010) use paper as the avoided product only one study uses pulp as the avoided product (Finnveden et al., 2000). It is thus likely that the benefits of paper recycling are thus overestimated to some extent.

\subsection{Plastics}

The updated WRAP study (WRAP, 2010) states that mechanical recycling is the preferred waste treatment comparing it to landfill and incineration with energy recovery (see Figure 19). Important for this conclusion is the assumption that the secondary plastics replace primary plastics one to one. In case of energy recovery it is important to realize that conventional plastics stem from fossil feedstock and the incineration of them contribute to the global warming potential thus minimising the difference with the incineration of fossil fuels used in the avoided energy.

Schonfield, 2004 assumes a 1:1 substitution of primary plastic by secondary in the base case for plastic recycling. In a sensitivity analysis another scenario is tested in which only $20 \%$ primary plastic is substituted and the remaining $80 \%$ is equally divided over wood and concrete plastic poles replacing wooden and concrete poles (Schonfield, 2004). This scenario may lead to recycling from having a negative global warming impact to a positive one. For recycling of PE, PP, PET and PVC fractions a change from -620 to $439 \mathrm{~kg} \mathrm{CO}_{2}$-eq per tonne recycled occurred and for recycling of PE and PP fractions the change was from - 464 to 415 


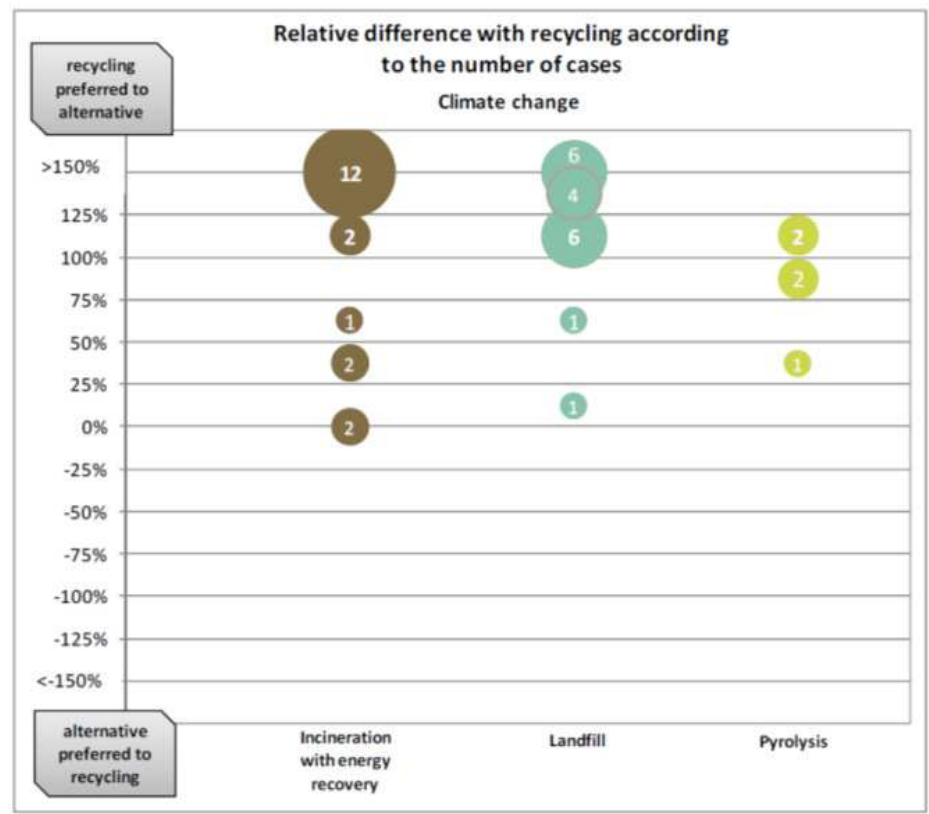

Fig. 19. Relative difference between the impacts from the different end-of-life options vs. recycling for climate change for plastics. The size of the "bubble" is proportional to the number of cases coming up with a value within the same range as another (WRAP, 2010).

$\mathrm{kg} \mathrm{CO}$-eq per tonne plastics recycled. The correct representation of the avoided primary products is thus crucial. Schonfield, 2004 postulates that when the substitution rate is below $70 \%$ other alternatives such as conversion to solid recovered fuel for cement kilns may be preferred.

Also other authors often assume a 1:1 substitution ratio as was found by Lazarevic et al., 2010. Only a limited number of LCA practitioners use a lower substitution ratio of e.g. 1:0.8 to address the loss in inherent properties of the plastic (Lazarevic et al., 2010). Ligthart \& Ansems, 2007 used the economic value of the secondary raw material derived from waste plastic cups as a factor to correct for the quality loss using the substitution approach. This is an approach that lies between the substitution approach and the value-corrected substitution. It does not however translate the amounts of secondary raw materials entering the product system to an amount of primary raw material.

Shen et al., 2011 compared a system (reference system) in which the post-consumer waste of PET of used bottles and fibres is send to an MSWI with energy recovery with a system in which an open-loop recycling takes place. In this open loop system the secondary PET replaces part of the primary PET used for bottles and fibres. Some PET is still lost from the system and is send to an MSWI. The lost PET is replenished with virgin PET. Both systems apply system expansion to avoid allocation. The study shows that also in case when no allocation (for the recycled PET) is needed recycling reduces the environmental impact of a system (see example for NREU in Figure 20). 


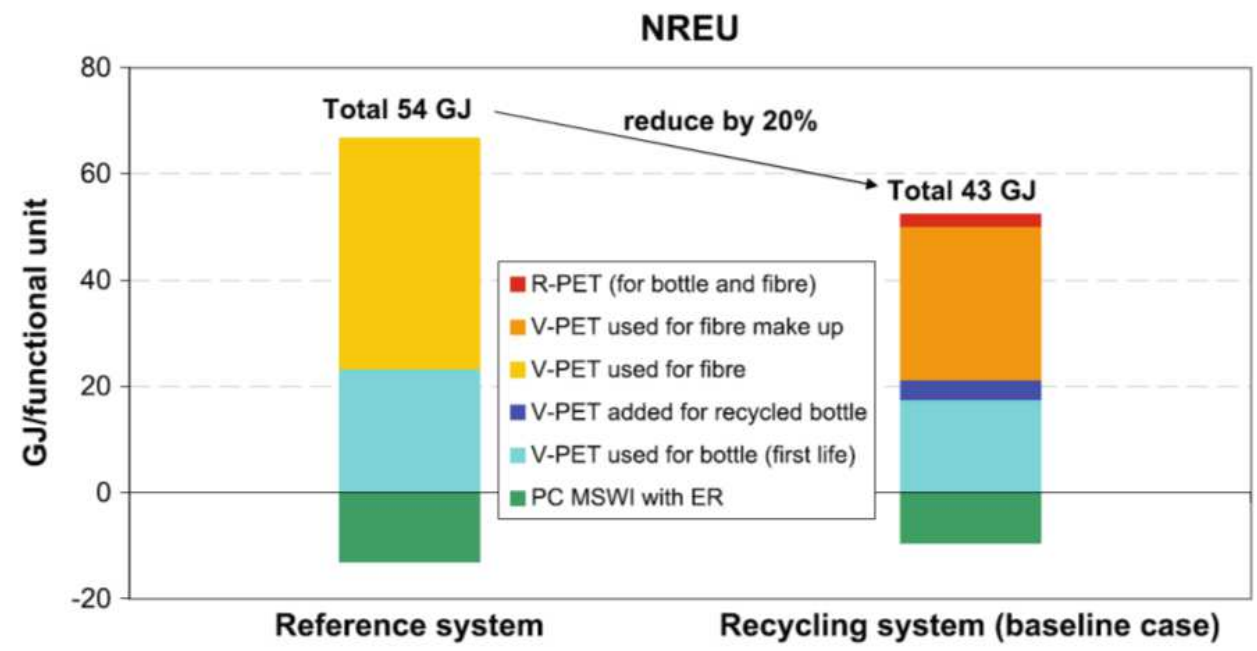

Fig. 20. Cradle-to-grave non-renewable energy use (NREU) recycling system and the reference system in which no recycling takes place (Schen et al., 2011).

Some authors like Williams et al., 2010 who studied the use of mixed plastic as a sports field drainage system are able to avoid allocation by system expansion. The system is however relatively simple as in the End-of-Life stage all waste goes to final disposal and no waste is being recycled.

\subsection{Metals}

The end-of-life of metals takes a special position in LCA because other than recycling there are no other end-of-life treatments, other than product re-use, that could have an environmental benefit and comparison with other beneficial treatments is not likely.

However, metal recycling may be complex as metals may be present in the form of alloys. According to Dubreuil et al., 2010 there has been until recently neither a consistent perspective nor a set of recycling indicators available for the metals industry as a whole. As the amount of available scrap would be limiting the recycled content in metal products the cut-off approach that focuses the recycled content would be less suited for modelling the end-of-life of metals (Dubreuil et al., 2010). The substitution approach would be more suited as it considers the whole life cycle of the product including its end disposition. This method is based on the premise that materials not recycled are replaced by primary materials.

Dubreuil et al., 2010 consider four metal recycling types:

1. Closed metal loop

2. Alloy loop

3. Transfer to another metal pool

4. Metallurgical re-separation

In case the inherent properties of a material are such that after recycling, the recycled material can offset the production of virgin material, a closed-loop-based calculation of 
environmental burden can be applied (Dubreuil et al., 2010). This approach avoids the use of allocation models. In case a metal is transferred to another metal pool, not being an alloy like brass, and the waste metal has no function it can be seen as lost from the system.

\section{Conclusions}

First of all it must be said that there is no best or worst allocation approach in LCA. This however under the condition that the approaches discussed here are correctly applied in LCA.

The simple cut-off approach is straightforward and so the easiest to apply. However, it does not reflect the full consequences of recycling (see e.g. Ekvall \& Tillman 1997). The allocation approach of economic allocation that is based on the cut-off approach will often give results not very different from this approach. It seems that its added value is limited.

The substitution or avoided impact approach is most commonly used in LCAs in which recycling plays a role. Because it is based on the mass flow it's allocation basis is well defined. However, a change in inherent properties is not reflected in this method. A way to overcome this is to apply a correction factor for the loss in inherent properties. The main task when applying this approach is to find the proper primary material of which the production is being avoided. Heijungs \& Guinee (2007) however see the specification of the avoided processes as problematic. According to them the problem lies in the fact that what is being avoided is essentially not there. Still it is likely that the substitution approach will remain the most commonly used approach for allocation of recycling in LCA.

The method of value-corrected substitution has the advantage that it is equipped to deal with changes in inherent properties of the recycled material. It works best for materials which have a well established recycling market as the market price will reflect the quality of the material. Market distortions may lead to the price of the secondary material not fully reflecting its quality leading to a distorted estimation of the avoided environmental impact.

Although allocation should be avoided according to ISO, 2006 the allocation of the environmental impacts of recycling is necessary in practice for the non-closed loop systems. The system expansion needed to avoid allocation would include many other, not always well-known, product systems using the recycled material. Because well applied allocation uses clear rules and system boundaries it ensures coherency between different LCAs.

As the choice of the allocation approach for the End-of-Life may influence the ranking of alternatives (Nicholson et al., 2009) LCA studies should, in these cases were such an influence may be expected, assess the effects of using an other allocation approach in a sensitivity analysis.

\section{References}

Amato, A.; Brimacombe, L. \& Howard, N. (1996). Development of quantitative methodology for assessing embodied energy of recyclable and reusable materials/products Ironmaking and Steelmaking, 23 (3), pp. 235-241.

Arena, U.; Mastellone, M.L.; Perugini, F. \& Clift, R. (2004). Environmental assessment of paper waste management options by means of LCA methodology. Industrial and Engineering Chemistry Research, 43 (18), pp. 5702-5714 
Classen M.; Althaus H.-J.; Blaser S.; Doka G.; Jungbluth N. \& Tuchschmid M. (2009). Life Cycle Inventories of Metals. Final report ecoinvent data v2.1

Dubreuil, A.; Young, S.B.; Atherton, J. \& Gloria, T.P. (2010). Metals recycling maps and allocation procedures in life cycle assessment International Journal of Life Cycle Assessment, 15 (6), pp. 621-634.

EAA, (2007). Aluminium Recycling in LCA; http://www.eaa.net/upl/4/default/doc/Alu_recycling_LCA.pdf

Ekvall, T. \& Tillman, A.-M. (1997). Open-loop recycling: Criteria for allocation procedures; International Journal of Life Cycle Assessment 2(3) pp. 155-162

Finnveden, G.; Johansson, J.; Lind, P. \& Moberg, A. (2000). Life cycle assessment of energy from solid waste. Forskningsgruppen för mijöstrategiska studier, Stockholm, Sweden.

Five Winds International, (2007). Recycling Allocation: Summary of Best Practices for Use in Life Cycle Assessment; http:/ / www.zinc.org/resource_documents/recycling_lca.pdf

Frischknecht, R. (2010). LCI modelling approaches applied on recycling of materials in view of environmental sustainability, risk perception and eco-efficiency International Journal of Life Cycle Assessment, 15 (7), pp. 666-671.

Guinée J.B. (Ed.); Gorrée M.; Heijungs R.; Huppes G.; Kleijn R.; Wegener Sleeswijk A.; Udo de Haes H.A.; de Bruijn J.A.; van Duin R \& Huijbregts M.A.J. (2002). Handbook on Life Cycle Assessment: Operational Guide to the ISO Standards. Kluwer Academic Publishers. Dordrecht

http://cml.leiden.edu/research/industrialecology/researchprojects/finished/new -dutch-lca-guide.html

Guinée, J. B.; Heijungs, R. \& Huppes, G. (2004). Economic Allocation: Examples and Derived Decision Tree. International Journal of Life Cycle Assessment 9 (1) pp. 23 - 33 http://www.p2pays.org/ref/41/40525.pdf

Heijungs R. \& Guinee J.B. (2007). Allocation and "what-if" scenarios in life cycle assessment of waste management systems. Waste Management;27(8) pp. 997-1005. http://www.sciencedirect.com/science/article/B6VFR-4NDDSY43/2/1287345b1ec18bffb2b2e65077374ec0

Hischier R.; Weidema B.; Althaus H.-J.; Bauer C.; Doka G.; Dones R.; Frischknecht R.; Hellweg S.; Humbert S.; Jungbluth N.; Köllner T.; Loerincik Y.; Margni M. \& Nemecek T. (2010). Implementation of Life Cycle Impact Assessment Methods. Final report ecoinvent v2.2 No. 3. Swiss Centre for Life Cycle Inventories, Dübendorf, $\mathrm{CH}$.

ISO, (2006). ISO 14044:2006 Environmental management -- Life cycle assessment -- Requirements and guidelines.

Lazarevic D.; Aoustin, E; Buclet, N. \& Brandt, N. (2010). Plastic waste management in the context of a European recycling society: Comparing results and uncertainties in a life cycle perspective. Resources, Conservation and Recycling, Volume 55, Issue 2, December 2010, pp. 246-259

Ligthart, T.N. \& Ansems, A.M.M. (2007). Single use Cups or Reusable (coffee) Drinking. Systems: An Environmental Comparison. Date. October 2007. TNO report 2006-A-R0246(E)/B

Merrild, H.; Damgaard, A. \& Christensen, T.H. (2008). Life cycle assessment of waste paper management: The importance of technology data and system boundaries in assessing recycling and incineration. Resources, Conservation and Recycling, 52 (12), pp. 1391-1398. 
Nicholson, A.L.; Olivetti, E.A.; Gregory, J.R.; Field, F.R. \& Kirchain, R.E. (2009). End-of-life LCA allocation methods: Open loop recycling impacts on robustness of material selection decisions. Sustainable Systems and Technology, 2009. ISSST '09. IEEE International Symposium on, pp.1-6, 18-20 May 2009

Norgate T.E. (2004). Metal Recycling: An Assessment Using Life Cycle Energy Consumption as a Sustainability Indicator, December 2004 CSIRO Minerals Report DMR-2616

Schonfield, P. (2008). LCA of Management Options for Mixed Waste Plastics. WRAP report June 2008

Shen, L.; Worrell, E. \& Patel, M.K. (2010). Open-loop recycling: A LCA case study of PET bottle-to-fibre recycling Resources, Conservation and Recycling, 55 (1) pp. 34-52

Shen, L.; Nieuwlaar, E.; Worrell, E. \& Patel, M. (2011). Life cycle energy and GHG emissions of PET recycling: change-oriented effects. International Journal of Life Cycle Assessment 16(6) pp. 522-536

Thomas, J.-S. \& Broadbent C. (2007). Method to take into account material recycling and end of life in LCA. LCA Forum Lausanne, 22 November 2007.

http://www.lcaforum.ch/Portals/0/DF_Archive/DF33/Thomas\%20\%20ArcelorMittal\%20-\%20LCA\%20DF33.pdf

Vroonhof, J.; Schwencke, A.; Croezen, H. \& Potjer, B. (2002). Legislation using LCA concerning Aluminium Delft, CE, November, 2002

Werner, F. \& Richter, K., (2000). Economic Allocation in LCA: A Case Study About Aluminium Window Frames. International Journal of Life Cycle Assessment 5(2) pp. 79-83. 2000. http://dx.doi.org/10.1007/BF02979727

Williams, T. G.J.L.; Heidrich, O. \& Sallis, P.J. (2010). A case study of the open-loop recycling of mixed plastic waste for use in a sports-field drainage system. Resources, Conservation and Recycling 55 pp. 118-128

WRAP (2006) Environmental benefits of recycling. An international review of life cycle comparisons for key materials in the UK recycling sector. May 2006.

WRAP (2010) Environmental benefits of recycling - 2010 update. March 2010

Zamagni A. (2008) Critical review of the current research needs and limitations related to ISO-LCA practice. Deliverable D7 of work package 5 of the CALCAS project. 2008 http://www.leidenuniv.nl/cml/ssp/publications/calcas_report_d7.pdf 


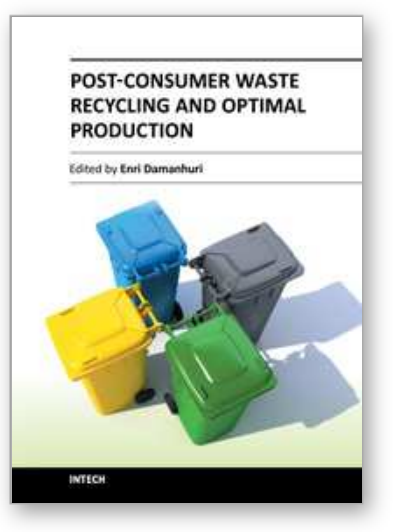

\author{
Post-Consumer Waste Recycling and Optimal Production \\ Edited by Prof. Enri Damanhuri
}

ISBN 978-953-51-0632-6

Hard cover, 294 pages

Publisher InTech

Published online 23, May, 2012

Published in print edition May, 2012

This book deals with several aspects of waste material recycling. It is divided into three sections. The first section explains the roles of stakeholders, both informal and formal sectors, in post-consumer waste activities. It also discusses waste collection programs for recycling. The second section discusses the analysis tools for recycling system. The third section focuses on the recycling process and optimal production. I hope that this book will convey both the need and means for recycling and resource conservation activities to a wide readership, at both academician and professional level, and contribute to the creation of a sound materialcycle society.

\title{
How to reference
}

In order to correctly reference this scholarly work, feel free to copy and paste the following:

Tom N. Ligthart and Toon (A.)M.M. Ansems (2012). Modelling of Recycling in LCA, Post-Consumer Waste Recycling and Optimal Production, Prof. Enri Damanhuri (Ed.), ISBN: 978-953-51-0632-6, InTech, Available from: http://www.intechopen.com/books/post-consumer-waste-recycling-and-optimal-production/modelling-ofrecycling-in-Ica

\section{INTECH}

open science | open minds

\section{InTech Europe}

University Campus STeP Ri Slavka Krautzeka 83/A 51000 Rijeka, Croatia Phone: +385 (51) 770447 Fax: +385 (51) 686166 www.intechopen.com

\section{InTech China}

Unit 405, Office Block, Hotel Equatorial Shanghai No.65, Yan An Road (West), Shanghai, 200040, China 中国上海市延安西路65号上海国际贵都大饭店办公楼405单元 Phone: +86-21-62489820

Fax: +86-21-62489821 
(C) 2012 The Author(s). Licensee IntechOpen. This is an open access article distributed under the terms of the Creative Commons Attribution 3.0 License, which permits unrestricted use, distribution, and reproduction in any medium, provided the original work is properly cited. 